\title{
Manifestações Cutâneas nas Mastocitoses: Atualização
}

\section{Cutaneous Manifestations in Mastocytosis: Update}

\author{
Sandra FERREIRA $\rrbracket^{1}$, lolanda FERNANDES ${ }^{1,2,3}$, Renata CABRAL ${ }^{2,3,4}$, Susana MACHADO ${ }^{1}$, Margarida LIMA $^{2,3,4}$, \\ Manuela SELORES 1,5 \\ Acta Med Port 2020 Apr;33(4):275-281 - https://doi.org/10.20344/amp.12189
}

\section{RESUMO}

Introdução: As mastocitoses caraterizam-se pela expansão clonal de mastócitos, com acumulação de mastócitos morfológica e imunofenotipicamente anormais em diferentes órgãos. A pele é o órgão mais frequentemente envolvido. Virtualmente, todas as crianças e mais de $80 \%$ dos adultos com mastocitose apresentam lesões cutâneas.

Material e Métodos: O presente artigo descreve os sinais e sintomas associados à mastocitose na pele, tendo por base a revisão das normas de orientação de consenso internacionais, recentemente publicadas.

Discussão: De acordo com a classificação proposta pela Organização Mundial de Saúde em 2016, a mastocitose divide-se em mastocitose cutânea, mastocitose sistémica e sarcoma de mastócitos. A mastocitose cutânea pode subdividir-se em três subtipos: a mastocitose cutânea maculopapular (também denominada urticária pigmentosa), mastocitose cutânea difusa e mastocitoma cutâneo. A telangiectasia macular eruptiva perstans já não é considerada uma entidade independente.

Conclusão: As manifestações cutâneas da mastocitose são variáveis, dependendo da idade de início da doença. Recentemente a classificação da mastocitose cutânea foi atualizada. Nas crianças, a mastocitose ocorre como mastocitose cutânea que tende à regressão espontânea durante a adolescência. Quando tem início na idade adulta, a mastocitose é geralmente sistémica, sendo a forma mais frequente a mastocitose sistémica indolente, que normalmente também cursa com manifestações cutâneas e tem um curso crónico.

Palavras-chave: Doenças da Pele; Mastocitose; Mastocitose Cutânea; Mastocitose Sistémica; Sarcoma de Mastócitos

\section{ABSTRACT}

Introduction: Mastocytosis is characterized by the clonal expansion of morphological and immunophenotypically abnormal mast cells in different organs. The skin is the most frequently affected tissue. Virtually all children and more than $80 \%$ of adult patients with mastocytosis show cutaneous lesions.

Material and Methods: The present article describes the symptoms and signs in cutaneous mastocytosis, based on the review of recently published international consensus guidelines.

Discussion: According to the 2016 World Health Organization classification, mastocytosis can be divided in cutaneous mastocytosis, systemic mastocytosis and mast cell sarcoma. Cutaneous mastocytosis is subclassified in three subtypes: maculopapular cutaneous mastocytosis, diffuse cutaneous mastocytosis and cutaneous mastocytoma. Telangiectasia macularis eruptiva perstans is no longer considered a distinct entity.

Conclusion: Based on the age of onset, cutaneous manifestations of mastocytosis can be variable. The classification of cutaneous mastocytosis has recently been updated. Typically, in patients with childhood-onset mastocytosis, the disease occurs as cutaneous mastocytosis and shows spontaneous resolution around puberty. In contrast, adult patients, despite having also cutaneous lesions, often show systemic involvement and the course of the disease is usually chronic.

Keywords: Mast-Cell Sarcoma; Mastocytosis; Mastocytosis, Cutaneous; Mastocytosis, Systemic; Skin Diseases

\section{INTRODUÇÃO}

As mastocitoses caraterizam-se pela expansão clonal de mastócitos, com acumulação de mastócitos morfológica e imunofenotipicamente anormais em diferentes órgãos. ${ }^{1}$

$\mathrm{Na}$ maioria dos doentes, a natureza clonal da doença pode ser estabelecida através da demonstração de mutações do gene KIT, que codifica o recetor KIT (CD117), uma proteína com atividade de cinase da tirosina, que regula o crescimento e a diferenciação dos mastócitos..$^{2,3}$

Pode atingir vários órgãos ou sistemas, nomeadamente, a pele, a medula óssea e os sistemas músculo-esquelético, gastrointestinal, cardiovascular, respiratório, nervoso central, entre outros. Não obstante, a pele é o órgão envol- vido com maior frequência. Praticamente todas as crianças e mais de $80 \%$ dos adultos com mastocitose apresentam lesões cutâneas. ${ }^{4}$

As manifestações clínicas das mastocitoses são bastante heterogéneas e os sintomas e sinais clínicos da doença resultam, quer da infiltração dos órgãos pelos mastócitos, quer da libertação de mediadores mastocitários com atividades biológicas diversificadas (histamina, triptase, heparina, e várias citocinas inflamatórias, entre outros). ${ }^{5,6}$

Do ponto de vista dermatológico, a clínica pode ser bastante variável, desde formas localizadas até quadros mais generalizados. Habitualmente manifesta-se através de

\footnotetext{
1. Serviço de Dermatologia. Hospital de Santo António. Centro Hospitalar e Universitário do Porto. Porto. Portugal.

2. Consulta Multidisciplinar de Linfomas Cutâneos e Mastocitoses. Hospital de Santo António. Centro Hospitalar e Universitário do Porto. Porto. Portugal.

3. Unidade Multidisciplinar de Investigação Biomédica. Instituto de Ciências Biomédicas Abel Salazar. Porto. Portugal.

4. Serviço de Hematologia. Hospital de Santo António. Centro Hospitalar e Universitário do Porto. Porto. Portugal.

5. Unidade de Investigação em Dermatologia. Hospital de Santo António. Centro Hospitalar e Universitário do Porto. Porto. Portugal.

$\triangle$ Autor correspondente: Sandra Ferreira. mf.sandraferreira@gmail.com

Recebido: 14 de abril de 2019 - Aceite: 01 de julho de 2019 | Copyright $\odot$ Ordem dos Médicos 2020
} 
lesões cutâneas eritemato-acastanhadas típicas, devido à infiltração da pele pelos mastócitos. Também podem ocorrer outros sinais e sintomas associados como prurido, flushing e lesões urticariformes, resultantes da libertação de mediadores mastocitários.

De acordo com a classificação proposta pela Organização Mundial de Saúde (OMS) em 2016, a mastocitose divide-se em mastocitose cutânea (MC), mastocitose sistémica (MS) e sarcoma de mastócitos. ${ }^{7,8}$

A MS ocorre normalmente na idade adulta. O achado patognomónico desta forma de mastocitose consiste na infiltração multifocal de mastócitos em vários órgãos internos, incluindo a medula óssea (MO). Os critérios diagnósticos da MS são categorizados em critério major e critérios minor. O critério major consiste na presença de agregados multifocais de mastócitos (pelo menos 15 mastócitos/agregado) atingindo um ou mais órgãos extra-cutâneos (geralmente documentado através do estudo da medula óssea). Os critérios minor incluem: a morfologia anormal dos mastócitos; a expressão de CD2 e/ou CD25 nos mastócitos; a presença da mutação no codão 816 do gene KIT (mais frequentemente a mutação D816V) em tecidos extracutâneos e a presença de uma concentração persistente de triptase sérica $>20 \mathrm{ng} / \mathrm{mL} .{ }^{7,8} \mathrm{O}$ diagnóstico de MS exige a presença do critério major em associação a pelo menos um critério minor e, na ausência do critério major, a presença de pelo menos três critérios minor.

Doentes com MS apresentam com frequência lesões cutâneas de mastocitose. Em doentes com lesões cutâneas típicas de mastocitose, nos quais não há cumprimento dos

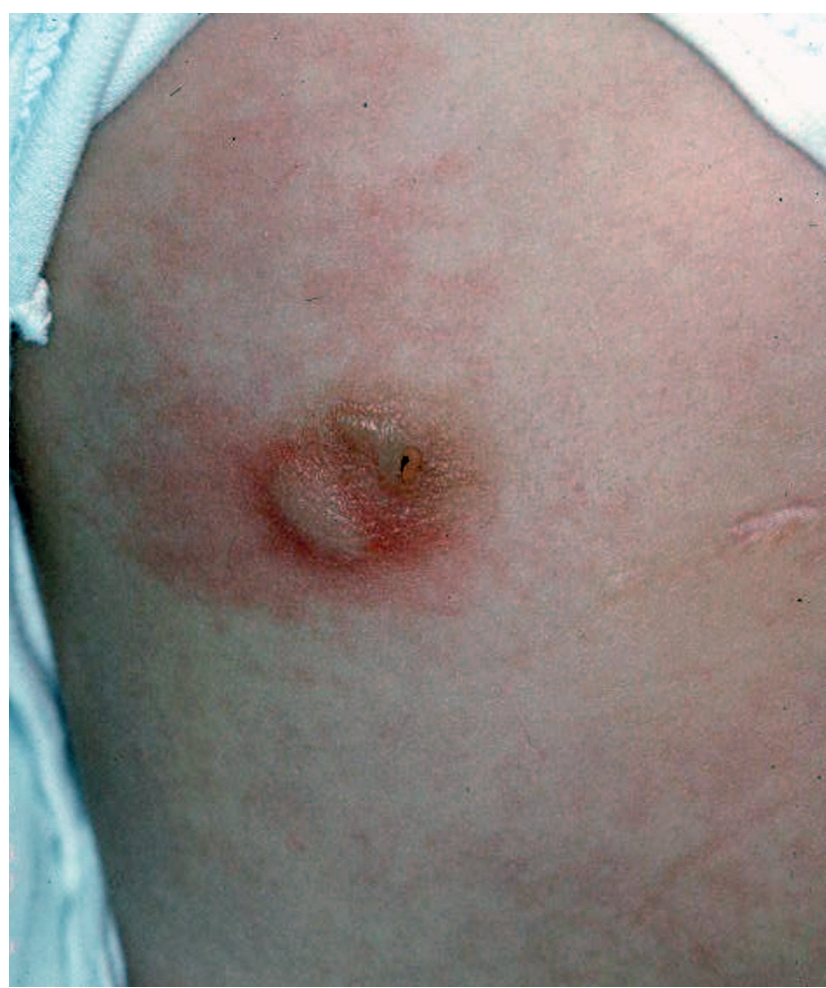

Figura 1 - Sinal de Darier: formação de pápula eritematosa, por vezes com formação de vesícula/bolha, após fricção de uma lesão de mastocitose critérios para o diagnóstico de MS, é efetuado o diagnóstico de MC. Esta é geralmente diagnosticada na infância e tem bom prognóstico.

Desta forma, o termo 'mastocitose cutânea' não é sinónimo da presença de 'mastocitose na pele'. Este último conceito tem emergido nos últimos anos, como sendo um diagnóstico provisório para os doentes que apresentam lesões cutâneas típicas de mastocitose, na ausência de estudo da medula óssea, que por sua vez, quando efetuado, permitirá o diagnóstico definitivo de mastocitose cutânea ou de mastocitose sistémica.

Mais de $80 \%$ dos doentes com mastocitose exibem lesões cutâneas eritemato-acastanhadas típicas de mastocitose..$^{9} \mathrm{O}$ sinal de Darier (Fig. 1), definido pela formação de pápula eritematosa, por vezes com formação de vesícula/ bolha, após fricção de uma lesão, é habitualmente demonstrável. ${ }^{10}$ Difere do dermografismo, na medida em que este último está presente também em pele não afetada. Constitui um importante achado diagnóstico, no entanto, pode não estar presente em todos os doentes, especialmente em adultos.

A classificação da MC baseia-se essencialmente nos achados macroscópicos das lesões cutâneas, na sua distribuição e na idade de início da doença. ${ }^{11,12}$ Adicionalmente, têm sido propostos diferentes tipos de $\mathrm{MC}$, com base na sua associação com a progressão e sintomas da doença. ${ }^{13}$

Em 2007, foram estabelecidos critérios que definem o envolvimento cutâneo em doentes com mastocitose. ${ }^{14}$ Estes critérios incluem a presença de lesões cutâneas típicas (critério major), o achado histológico de um infiltrado monomórfico de mastócitos consistindo em grandes agregados de mastócitos positivos para triptase (> 15 células/ agregado) ou mais de 20 mastócitos dispersos, por campo microscópico de alta resolução $(\times 40)$ (critério minor) e a deteção, na lesão cutânea, da mutação no codão 816 do gene KIT (critério minor). ${ }^{15} \mathrm{~A}$ mastocitose na pele é definida pela observação do exantema caraterístico, com o sinal de Darier positivo, que constitui o critério major, associada a pelo menos um dos critérios minor.

A classificação da OMS, globalmente aceite, subdivide a mastocitose cutânea em três subtipos: a mastocitose cutânea maculopapular (MCMP), também denominada urticária pigmentosa (Fig. 2), a mastocitose cutânea difusa (MCD) (Fig. 3) e o mastocitoma cutâneo (Fig. 4). ${ }^{8} \mathrm{~A}$ telangiectasia macular eruptiva perstans, anteriormente considerada como uma variante rara de mastocitose cutânea, caraterizada pela presença de máculas eritemato-acastanhadas telangiectásicas irregulares que desaparecem à diascopia, foi suprimida, não sendo atualmente classificada como uma entidade independente.

Apesar da implementação da classificação da MC pela OMS e dos critérios que definem o atingimento cutâneo em doentes com mastocitose, anteriormente referidos, constata-se ainda a necessidade de uma melhor definição de algumas subformas de manifestações cutâneas.

Uma vez diagnosticada a mastocitose na pele, é necessário avaliar a extensão clínica da doença. Para tal, 

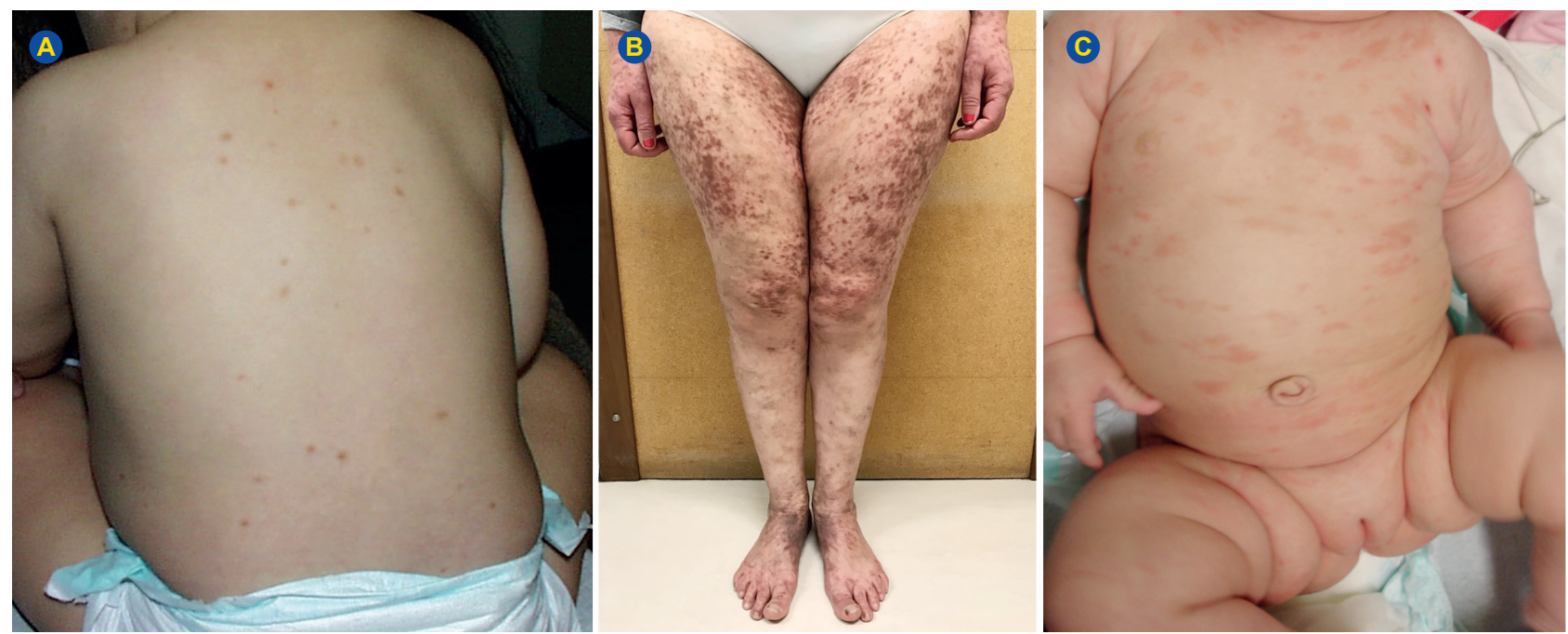

Figura 2 - Mastocitose cutânea maculopapular (urticaria pigmentosa) e suas variantes: mastocitose cutânea maculopapular monomórfica em idade pediátrica e na idade adulta ( $\mathrm{e}$ e $\mathrm{B}$, respetivamente) e mastocitose maculopapular polimórfica na criança (C)

poder-se-á recorrer ao índice SCORMA (SCORing MAstocytosis), que consiste na avaliação de três partes. A extensão do atingimento cutâneo é analisada na parte $A$, sob a forma de percentagem de superfície corporal afetada. Por definição, o mastocitoma cutâneo representa $1 \%$ da superfície corporal, enquanto que na $M C D$, considera-se que $100 \%$ da pele se encontra afetada. A intensidade da doença é avaliada na parte $B$, tendo em conta uma lesão cutânea típica representativa da maioria das lesões, idealmente em áreas não fotoexpostas. Nesta lesão é avaliada a pigmentação/eritema, vesiculação, infiltração e a presença de sinal de Darier. Cada item é classificado entre 0 e 3 ( 0 = ausência e 3 = severo). Finalmente, na parte $C$, são considerados cinco parâmetros (fatores desencadeantes, flushing, diarreia, prurido e dor óssea), que são classificados pelo paciente de acordo com a escala visual analógica, até ao valor máximo de $10(0=$ ausente e $10=$ persistente $)$. $A$ fórmula $A 5+5 B+2 C / 5$, é utilizada para calcular o índice final. $O$ valor final do índice SCORMA varia entre $5.2 \mathrm{e}$ 100. ${ }^{16,17}$ Atualmente, a forma mais rápida e eficaz de documentar a extensão clínica da doença cutânea é feita com

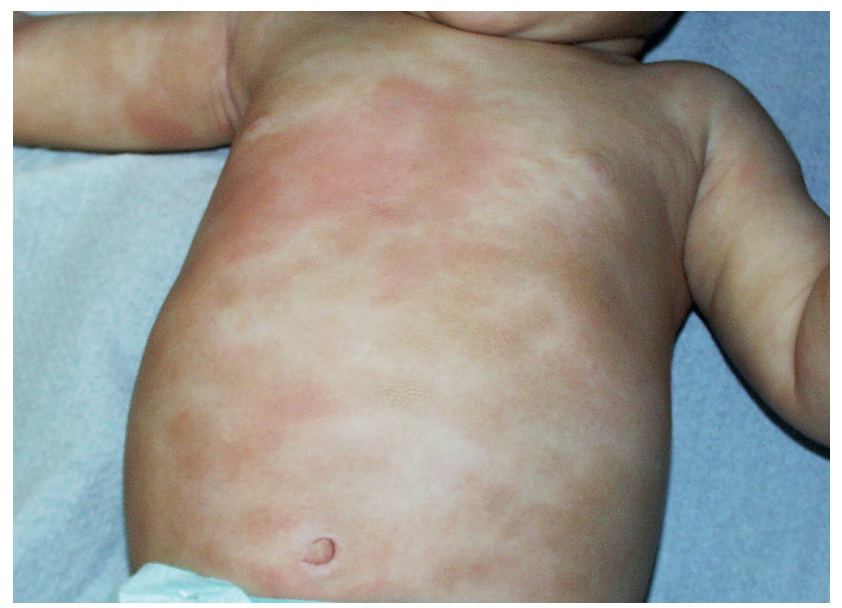

Figura 3 - Mastocitose cutânea difusa: observa-se um espessamento (paquidermia) e eritema generalizado da pele, atingindo praticamente toda a superfície corporal recurso ao registo fotográfico.

A heterogeneidade da mastocitose é evidenciada pelo facto de a doença poder ter início na idade pediátrica, geralmente como $\mathrm{MC}$, com tendência à regressão espontânea durante a adolescência, ou ter início na idade adulta, mais frequentemente como MS, mostrando um curso clínico crónico.

Por conseguinte, de acordo com a idade de início da doença, a apresentação clínica do envolvimento cutâneo em doentes com mastocitose é variável, pelo que se torna útil a sua divisão, tendo em conta esta premissa.

\section{MATERIAL E MÉTODOS}

Foram utilizados termos específicos como 'cutaneous mastocytosis', 'maculopapular cutaneous mastocytosis', 'cutaneous mastocytoma', 'diffuse cutaneous mastocytosis' e 'World Health Organization' para pesquisar, através da PubMed, artigos de revisão sobre mastocitoses publicados e indexados na MEDLINE, usando o motor de busca da PubMed. Através da leitura dos respetivos resumos, foram selecionados artigos para leitura do texto integral e

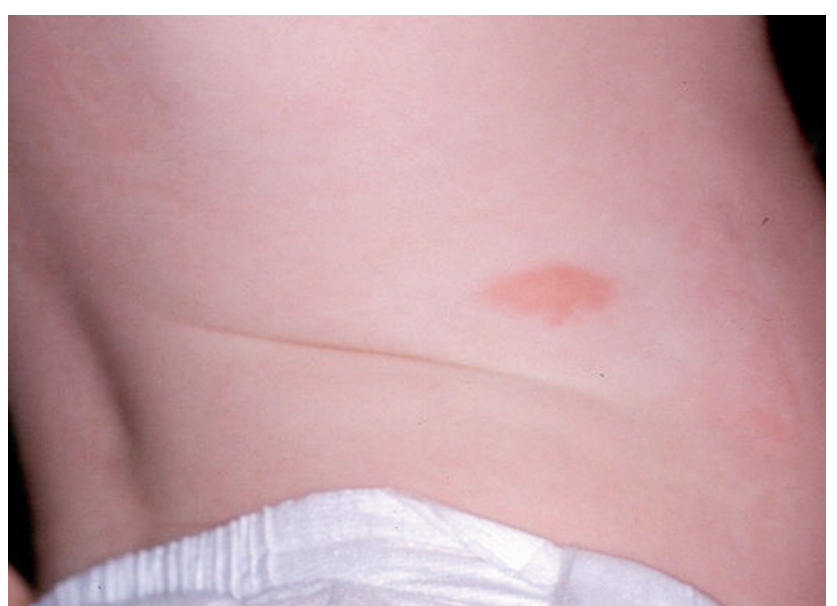

Figura 4 - Mastocitoma cutâneo, que geralmente ocorre sob a forma um nódulo ou placa, amarelo-acastanhada 
consultadas as respetivas referências, que, por sua vez, permitiram a seleção de outros artigos relevantes. Foi dada particular atenção à classificação da OMS, recentemente atualizada e às normas orientadoras de consenso internacional.

\section{DISCUSSÃO}

\section{Manifestações cutâneas das mastocitoses}

A mastocitose pode ocorrer em qualquer idade. $\mathrm{Na}$ infância, é frequente o início durante os primeiros seis meses de vida, podendo, inclusivamente, estar presente ao nascimento. A maioria dos adultos desenvolve a doença entre os 20 e os 35 anos.

As três principais formas de envolvimento cutâneo na mastocitose, reconhecidas pela OMS, são: a mastocitose cutânea maculopapular, a mastocitose cutânea difusa e o mastocitoma cutâneo.

\section{Mastocitose cutânea maculopapular}

De acordo com um Grupo de Consenso Europeu e Americano, em doentes com MCMP é relevante a subclassificação em duas variantes: a MCMP monomórfica e a MCMP polimórfica (Fig. 2). ${ }^{15,16}$ O propósito desta classificação está relacionado com o potencial impacto prognóstico em termos de duração da doença na idade pediátrica, pois as lesões polimórficas tendem a regredir durante a adolescência, enquanto que nas crianças com a variante monomórfica, esta tende a persistir durante a idade adulta, geralmente como mastocitose sistémica.

Variante polimórfica: A maioria das crianças apresenta a variante polimórfica, caraterizada pela presença de vários tipos de lesões cutâneas eritemato-acastanhadas, incluindo máculas, pápulas, placas ou nódulos, de diferentes formas e tamanhos, geralmente mal delimitadas, com contornos irregulares, com ou sem infiltração. São maiores do que as lesões encontradas na variante monomórfica, frequentemente observada nos adultos. Alguns quadros clínicos são dominados pela presença de nódulos ou placas, anteriormente designados de 'mastocitose nodular' ou 'em placas', respetivamente..$^{10,18} \mathrm{O}$ tipo de lesões varia ao longo do curso evolutivo da doença, com tendência à regressão espontânea. A distribuição é assimétrica e generalizada, com envolvimento habitual da cabeça, pescoço e extremidades. O sinal de Darier é correntemente observado, podendo inclusivamente desencadear a formação de bolhas. Embora o estudo medular, por norma, não seja efetuado nestes doentes, assume-se que se trata de uma mastocitose cutânea, sem envolvimento sistémico. A triptase é habitualmente normal. O prognóstico é favorável, constatando-se a remissão espontânea durante a adolescência na esmagadora maioria dos casos. ${ }^{19}$ Raramente, os nódulos podem persistir durante a idade adulta, podendo adquirir caraterísticas de mastocitose sistémica bem diferenciada, uma forma muito rara de mastocitose, em que os mastócitos têm caraterísticas morfológicas, fenotípicas e genéticas distintas: são redondos e bem granulados, têm expressão aberrante de CD30, não expressam CD25 e não apresentam a mutação KIT D816V. ${ }^{20,21}$

Variante monomórfica: Numa pequena percentagem de crianças, observa-se a variante monomórfica, homogénea, caraterizada pela presença de pequenas máculas e pápulas eritemato-acastanhadas, redondas ou ovaladas, semelhante à clínica observada em adultos. O seu número é altamente variável e mostram uma distribuição centrífuga. ${ }^{4}$ Nestes doentes podem verificar-se níveis elevados de triptase sérica, que não diminuem ao longo do tempo, podendo, inclusivamente, mostrar envolvimento sistémico. ${ }^{16,22}$ É habitual a sua persistência durante a idade adulta sob a forma de MS. ${ }^{22}$

$\mathrm{Na}$ idade adulta, o quadro clínico cutâneo carateriza-se pela presença de pequenas máculas eritemato-acastanhadas, arredondadas, infracentimétricas, com aspeto monomórfico, variante clínica anteriormente designada de urticaria pigmentosa. ${ }^{23,24} \mathrm{O}$ número de lesões é muito variável, existindo doentes que apresentam um número reduzido de lesões cutâneas, enquanto outros, pelo contrário, mostram atingimento de praticamente toda a superfície corporal. Geralmente as lesões cutâneas têm início ao nível das coxas, axilas e região inferior do tronco, com progressão posterior para as extremidades.

A extensão do atingimento cutâneo pode correlacionar-se com a extensão do envolvimento sistémico e com os níveis de triptase.$^{25} \mathrm{~A}$ maioria dos doentes adultos com lesões maculopapulares apresentam envolvimento da medula óssea, pelo que não correspondem a verdadeiros casos de mastocitose cutânea maculopapular, mas sim a quadros de MS, geralmente de mastocitose sistémica indolente (MSI), com lesões cutâneas maculopapulares. Do ponto de vista dermatológico, a apresentação clínica é semelhante entre os doentes com ou sem envolvimento sistémico. Quadros clínicos dermatológicos similares podem ocorrer também em doentes com doença sistémica avançada, como na MS agressiva e na MS com neoplasia hematológica associada. Nestes casos, as lesões tendem a confluir e podem regredir ao longo do tempo, estimando-se que apenas $50 \%$ dos doentes com MS avançada apresentem lesões cutâneas, enquanto $95 \%$ dos doentes com MSI mostram envolvimento cutâneo.

Raramente, alguns doentes podem exibir telangiectasias. ${ }^{26}$ Tipicamente estas lesões consistem em pequenas máculas telangiectásicas, eritemato-acastanhadas, irregulares, sobre um fundo acastanhado. ${ }^{26}$ É frequente coexistirem com lesões maculopapulares noutras regiões corporais. Classicamente desaparecem à diascopia. As lesões localizam-se sobretudo no tronco e extremidades proximais, com padrão simétrico e sem prurido associado. O sinal de Darier é habitualmente negativo ou positivo fraco, devido ao reduzido número de mastócitos envolvidos. O diagnóstico é baseado na clínica e confirmado pelos achados histológicos, que mostram a localização preferencial dos mastócitos em torno dos capilares e vénulas do plexo venoso superficial no $1 / 3$ superior da derme. ${ }^{26,27}$ Tendo em conta um estudo recente, estima-se que o envolvimento sistémico ocorra em cerca de $47 \%$ destes doentes. ${ }^{28}$ 
A telangiectasia macularis eruptiva perstans já não é considerada uma entidade distinta.

Menos frequentemente, os adultos podem apresentar a forma polimórfica da doença cutânea, com lesões cutâneas de diferentes formas e tamanhos, em placa ou nódulos.

Esta variante tem início habitual durante a infância e não está associada à mutação D816V do gene KIT. Em casos muito raros, pode ter caraterísticas de mastocitose sistémica bem diferenciada.

\section{Mastocitose cutânea difusa}

Esta forma de mastocitose cutânea é rara e geralmente está presente ao nascimento ou desenvolve-se logo após. ${ }^{4,15}$

A MCD define-se pelo espessamento (paquidermia) e eritema generalizado da pele, atingindo praticamente toda a superfície corporal, na ausência de lesões cutâneas hiperpigmentadas individualizadas. ${ }^{4,15}$ Muitas vezes é referida metaforicamente como 'peau d'orange', 'elephant skin' ou 'crocodile-like pachydermia'. ${ }^{4}$ Podem ocorrer pápulas, especialmente em áreas de paquidermia acentuada. $\mathrm{O}$ dermografismo é observado com frequência nestes doentes, assim como a formação fácil de bolhas, após a fricção acidental. Devido à elevada densidade de mastócitos presentes na pele, não é recomendada a pesquisa do sinal de Darier, no sentido de evitar a desgranulação maciça dos mastócitos, que pode conduzir a sinais e sintomas potencialmente graves, como hipotensão, flushing e sintomas gastrointestinais, requerendo a administração de adrenalina. ${ }^{25}$

Nos estadios iniciais da doença, os níveis de triptase sérica estão tipicamente aumentados (frequentemente > $100 \mathrm{ng} / \mathrm{mL}$ ), no entanto tendem a diminuir ao longo do tempo. ${ }^{29}$ Apesar da extensão do atingimento cutâneo e da sintomatologia proeminente associada, a maioria dos doentes não tem envolvimento sistémico e a doença tende a resolver espontaneamente durante a adolescência, resultando numa aparência cutânea de 'cutis laxa-like' residual. ${ }^{4}$ No entanto, em alguns casos pode persistir durante a idade adulta, adquirindo caraterísticas de mastocitose sistémica bem diferenciada. ${ }^{4,30}$

\section{Mastocitoma cutâneo}

Outra forma de mastocitose cutânea, frequentemente observada na criança, é o mastocitoma cutâneo.

Geralmente ocorre sob a forma de lesão única, um nódulo ou placa, amarelo-acastanhada, com formação frequente de bolha. Em alguns casos, pode estar presente mais do que uma lesão. Atualmente, considera-se que o termo mastocitoma pode englobar, no máximo, três lesões cutâneas. ${ }^{15}$ É frequente o envolvimento do tronco e extremidades, no entanto pode ocorrer noutras localizações. $\mathrm{Na}$ maioria dos casos, está presente ao nascimento ou desenvolve-se nos primeiros meses de vida, sendo muitíssimo raro na idade adulta. Na prática clínica, o diagnóstico baseia-se exclusivamente na clínica, não sendo necessária a realização de biopsia cutânea. ${ }^{4}$
Os achados histológicos do mastocitoma são indistinguíveis dos observados na MCD, caraterizando-se pela infiltração massiva por mastócitos que ocupam praticamente toda a derme..$^{18}$ Por conseguinte, é expectável que o sinal de Darier esteja presente em praticamente todos os casos, no entanto, pelos motivos acima apontados, não se recomenda a sua pesquisa.

Os níveis séricos da triptase são geralmente normais e não se verifica envolvimento sistémico.

Apresenta um padrão dinâmico, podendo aumentar de dimensões (mas não em número), evoluir para outro tipo de lesão cutânea elementar e finalmente regredir após períodos variáveis de tempo, não persistindo durante a idade adulta. ${ }^{31}$

Torna-se importante ressalvar que a delimitação entre os subtipos de envolvimento cutâneo na mastocitose não é estanque, pois alguns doentes apresentam lesões cutâneas que não se enquadram perfeitamente em nenhuma das subformas e variantes atualmente aceites. ${ }^{4}$ Podem encontrar-se casos com sobreposições clínicas, especialmente entre as variantes extensas da MCMP polimórfica e a MCD, assim como entre a variante polimórfica da MCMP e o mastocitoma, quando estão presentes mais do que uma lesão. ${ }^{15}$ Além disso, raramente, as lesões cutâneas podem estar restritas a determinadas áreas corporais segmentares, representando casos de mosaicismo da doença. ${ }^{32}$

Quer a mastocitose cutânea difusa, quer o mastocitoma cutâneo, constituem formas praticamente inexistentes na idade adulta. Quando observadas, exibem caraterísticas clínicas semelhantes às observadas na infância.

\section{Achados dermatoscópicos nas diferentes variantes de 'mastocitose na pele'}

A dermatoscopia consiste numa técnica não invasiva que permite uma rápida observação e avaliação da microestrutura da epiderme, da junção dermo-epidérmica e da derme papilar. Nos últimos anos, tem sido amplamente utilizada como meio complementar em múltiplas dermatoses, inclusive na mastocitose.

De acordo com um estudo realizado por Vano-Galvan et al, que incluiu 127 doentes com 'mastocitose na pele', foram identificados essencialmente quatro padrões distintos, com recurso à dermatoscopia. O padrão em "mancha castanha", caraterizado pela presença de uma mancha castanha clara difusa, sem outros achados identificáveis, foi o mais frequentemente observado, estando presente maioritariamente em doentes com mastocitose em placa e maculopapular. Outros padrões identificados, incluíram, por ordem decrescente de frequência, em 'rede pigmentar', 'reticular vascular' e em 'mancha amarelo-alaranjada', típico dos mastocitomas. ${ }^{33}$

\section{Outras manifestações associadas à 'mastocitose na pele' \\ O prurido está presente quer em doentes em idade} pediátrica, quer na idade adulta. Estima-se que ocorra em 
cerca de $84,2 \%$ dos doentes adultos. Os mastócitos funcionam como uma 'power house', que quando ativados, libertam múltiplos mediadores pruritogénicos que iniciam uma comunicação recíproca com nociceptores específicos nas fibras nervosas sensitivas. ${ }^{34}$ Consequentemente, as fibras nervosas libertam neuropeptídeos vasoativos e inflamatórios, que, por sua vez, ativam os mastócitos, num mecanismo de feedback, conduzindo à inflamação neurogénica e consequentemente ao prurido. ${ }^{34}$

A formação de bolhas está praticamente restrita aos doentes em idade pediátrica, sendo particularmente frequente em idades mais precoces ( $<2$ anos) e em doentes que têm um envolvimento cutâneo extenso ou que apresentem lesões mais infiltradas em áreas mais suscetíveis à fricção.

O flushing resulta do aumento do fluxo sanguíneo na pele devido à libertação de sustâncias vasoativas pelos mastócitos. A presença deste sintoma pode conduzir ao desenvolvimento de complicações sérias, nomeadamente o colapso cardiovascular. ${ }^{35}$

Os doentes com 'mastocitose na pele' podem sofrer de múltiplos outros sintomas (sistémicos), incluindo dor abdominal, diarreia, dores ósseas, cefaleias, depressão, reações alérgicas, entre outros. Embora as manifestações sistémicas sejam observadas maioritariamente em doentes adultos, devido ao frequente envolvimento sistémico pela doença, podem também ocorrer em crianças, nas quais a doença está confinada à pele. Isto porque as manifestações sistémicas podem estar associadas com a libertação de mediadores pelos mastócitos cutâneos, com predomínio em casos com envolvimento cutâneo extenso. ${ }^{4}$

\section{CONCLUSÃO}

Em resumo, a mastocitose pode ocorrer quer em idade pediátrica, quer na idade adulta, existindo, no entanto, inúmeras diferenças entre os dois grupos.

$\mathrm{Na}$ idade adulta, as lesões cutâneas estão geralmente associadas ao envolvimento sistémico, contrariamente ao observado na infância. Com frequência, na idade adulta, a doença tem um curso clínico crónico, enquanto que na criança, habitualmente, ocorre resolução espontânea durante a adolescência. Mais de $80 \%$ dos doentes adultos revelam a mutação KIT D816V, presente em apenas 35\% das crianças; cerca de $40 \%$ destas últimas expressam outras mutações do gene KIT e em aproximadamente $25 \%$ dos casos não é detetada qualquer mutação. ${ }^{36}$

Em relação às manifestações cutâneas, na criança, o subtipo de mastocitose mais frequente é a MCMP (40\%$70 \%)$, seguido pelo mastocitoma (20\% - 50\%) e pela MCD ( $3 \%-8 \%$ ), enquanto que nos doentes adultos, a forma mais frequente de envolvimento cutâneo é a MCMP (> 95\%). ${ }^{4}$

A subdivisão da MCMP em variante monomórfica e polimórfica tem impacto prognóstico, na medida em que a maioria das crianças com a variante polimórfica da MCMP apresenta níveis de triptase sérica normais, observando-se a regressão espontânea durante a adolescência, enquanto que os doentes pediátricos com variante monomórfica da MCMP geralmente têm níveis elevados de triptase sérica, revelando maior probabilidade de persistência da doença na idade adulta.

Apesar das atualizações recentes, a classificação atual da mastocitose cutânea não é totalmente satisfatória. Espera-se, no futuro, uma maior acuidade na classificação destas doenças, tendo em conta a constante evolução em relação a diferentes padrões histológicos, imunohistoquímicos e genéticos.

\section{PROTECÇÃO DE PESSOAS E ANIMAIS}

Os autores declaram que os procedimentos seguidos estavam de acordo com os regulamentos estabelecidos pelos responsáveis da Comissão de Investigação Clínica e Ética e de acordo com a Declaração de Helsínquia da Associação Médica Mundial.

\section{CONFIDENCIALIDADE DOS DADOS}

Os autores declaram ter seguido os protocolos do seu centro de trabalho acerca da publicação de dados.

\section{CONFLITOS DE INTERESSE}

Os autores declaram não ter qualquer conflito de interesse relativamente ao presente artigo.

\section{FONTES DE FINANCIAMENTO}

Este trabalho não recebeu qualquer tipo de suporte financeiro de nenhuma entidade no domínio público ou privado.

\section{REFERÊNCIAS}

1. Fernandes IC, Teixeira M dos A, Freitas I, Selores M, Alves R, Lima M. Adult mastocytosis: a review of the Santo António Hospital 's experience and an evaluation of World Health Organization criteria for the diagnosis of systemic disease. An Bras Dermatol. 2014;89:59-66.

2. Arock M, Sotlar K, Akin C, Broesby-Olsen S, Hoermann G, Escribano L, et al. KIT mutation analysis in mast cell neoplasms: recommendations of the European competence network on mastocytosis. Leukemia. 2015;29:1223-32.

3. Garcia-Montero AC, Jara-Acevedo M, Teodosio C, Sanchez ML, Nunez R, Prados A, et al. KIT mutation in mast cells and other bone marrow haematopoietic cell lineages in systemic mast cell disorders. A prospective study of the Spanish Network on Mastocytosis (REMA) in a series of 113 patients. Blood. 2006;108:2366-72.

4. Matito A, Azaña JM, Torrelo A, Alvarez-Twose I. Cutaneous mastocytosis

in adults and children: new classification and prognostic factors. Immunol Allergy Clin North Am. 2018;38:351-63.

5. Moon TC, Befus AD, Kulka M. Mast cell mediators: their differential release and the secretory pathways involved. Front Immunol. 2014;5:569.

6. Metcalfe DD. Mast cells and mastocytosis. Blood. 2008;112:946-56.

7. Pardanani A. Systemic mastocytosis in adults: 2017 update on diagnosis, risk stratification and management. Am J Hematol. 2016;91:1146-59.

8. Valent P, Akin C, Metcalfe DD. Mastocytosis: 2016 updated WHO classification and novel emerging treatment concepts. Blood. 2017;129:1420-7.

9. Akin C, Metcalfe DD. Systemic mastocytosis. Annu Rev Med. 2004;55:419-32.

10. Hartmann K, Henz BM. Cutaneous mastocytosis-clinical heterogeneity. 
Int Arch Allergy Immunol. 2002;127:143-6.

11. Hartmann K, Henz BM. Classification of cutaneous mastocytosis: a modified consensus proposal. Leuk Res. 2002;26:485-6.

12. Hartmann K, Henz BM. Mastocytosis: recent advances in defining the disease. Br J Dermatol. 2001;144:682-95.

13. Alvarez-Twose I, Vano-Galvan S, Sanchez-Munoz L, Morgado JM, Matito A, Torrelo A, et al. Increased serum baseline tryptase levels and extensive skin involvement are predictors for the severity of mast cell activation episodes in children with mastocytosis. Allergy. 2012;67:81321.

14. Valent P, Akin C, Escribano L, Fodinger M, Hartmann K, Brockow K, et al. Standards and standardization in mastocytosis: consensus statements on diagnostics, treatment recommendations and response criteria. Eur $\mathrm{J}$ Clin Invest. 2007:37:435-53.

15. Hartmann K, Escribano L, Grattan C, Brockow K, Carter MC, AlvarezTwose I, et al. Cutaneous manifestations in patients with mastocytosis: Consensus Report of the European Competence Network on Mastocytosis; the American Academy of Allergy, Asthma \& Immunology; and the European Academy of Allergology and Clinical Immunology. J Allergy Clin Immunol. 2016;137:35-45.

16. Heide R, Middelkamp Hup MA, Mulder PG, Oranje AP; Mastocytosis Study Group Rotterdam. Clinical scoring of cutaneous mastocytosis. Acta Derm Venereol. 2001;81:273-6.

17. Heide R, van Doorn K, Mulder PG, van Toorenenbergen AW, Beishuizen $A$, de Groot $\mathrm{H}$, et al. Serum tryptase and SCORMA (SCORing MAstocytosis) Index as disease severity parameters in childhood and adult cutaneous mastocytosis. Clin Exp Dermatol. 2009;34:462-8.

18. Wolff K, Komar M, Petzelbauer P. Clinical and histopathological aspects of cutaneous mastocytosis. Leuk Res. 2001;25:519-28.

19. Wiechers T, Rabenhorst A, Schick T, Preussner LM, Förster A, Valent $\mathrm{P}$, et al. Large maculopapular cutaneous lesions are associated with favorable outcome in childhood-onset mastocytosis. J Allergy Clin Immunol. 2015;136:1581-90.

20. Chan EC, Bai Y, Kirshenbaum AS, Fischer ER, Simakova O, Bandara $\mathrm{G}$, et al. Mastocytosis associated with a rare germline KIT K509l mutation displays a well-differentiated mast cell phenotype. J Allergy Clin Immunol. 2014;134:178-87.

21. Akin C, Escribano L, Nuñez R, Garcia-Montero A, Angulo M, Orfao A, et al. Well-differentiated systemic mastocytosis: a new disease variant with mature mast cell phenotype and lack of codon $816 \mathrm{c}$-Kit mutations. J Allergy Clin Immunol. 2004;113:S327.

22. Lange M, Nedoszytko B, Gorska A, Zawrocki A, Sobjanek M, Kozlowski D. Mastocytosis in children and adults: clinical disease heterogeneity. Arch Med Sci. 2012;8:533-41.
23. Metcalfe DD. Classification and diagnosis of mastocytosis: current status. J Invest. Dermatol. 1991;96:2S-4.

24. Czarnetzki BM, Behrendt $\mathrm{H}$. Urticaria pigmentosa: clinical picture and response to oral disodium cromoglycate. Br J Dermatol. 1981;105:5637.

25. Brockow K, Akin C, Huber M, Metcalfe DD. Assessment of the extent of cutaneous involvement in children and adults with mastocytosis: relationship to symptomatology, tryptase levels, and bone marrow pathology. J Am Acad Dermatol. 2003;48:508-16.

26. Watkins CE, Bokor WB, Leicht S, Youngberg G, Krishnaswamy G. Telangiectasia macularis eruptiva perstans: more than skin deep. Dermatol Reports. 2011;3:e12.

27. Betti R, Vergani R, Tolomio E, Martino P, Crosti C. Guess what! Telangiectasia macularis eruptiva perstans involving the upper arms in an adult male. Eur J Dermatol. 2000;10:563-4.

28. Severino M, Chandesris MO, Barete S, Tournier E, Sans B, Laurent $\mathrm{C}$, et al. Telangiectasia macularis eruptiva perstans (TMEP): a form of cutaneous mastocytosis with potential systemic involvement. J Am Acad Dermatol. 2016;74:885-91.

29. Alvarez-Twose I, Vañó-Galván S, Sanchez-Muñoz L, Morgado JM, Matito A, Torrelo A, et al. Increased serum baseline tryptase levels and extensive skin involvement are predictors for the severity of mast cell activation episodes in children with mastocytosis. Allergy. 2012;67:81321.

30. Alvarez-Twose I, Jara-Acevedo M, Morgado JM, García-Montero A, Sánchez-Muñoz L, Teodósio C, et al. Clinical, immunophenotypic, and molecular characteristics of well-differentiated systemic mastocytosis. J Allergy Clin Immunol. 2016;137:168-78.

31. Azaña JM, Velasco E, Torrelo A. Mastocitomas: revisión de 33 casos infantiles. Actas Dermosifiliogr. 1993;84:559-62.

32. Merika EE, Bunker CB, Francis N, Singh S. A segmental rash in a young male: a quiz. Naevoid urticaria pigmentosa. Acta Derm Venereol. 2014;94:253-4

33. Vano-Galvan S, Alvarez-Twose I, De las Heras E, Morgado JM, Matito A, Sánchez-Muñoz L, et al. Dermoscopic features of skin lesions in patients with mastocytosis. Arch Dermatol. 2011;147:932-40.

34. Gupta K, Harvima IT. Mast cell-neural interactions contribute to pain and itch. Immunol Rev. 2018;282:168-87.

35. Brockow K, Ring J, Alvarez-Twose I, Orfao A, Escribano L. Extensive blistering is a predictor for severe complications in children with mastocytosis. Allergy. 2012;67:1323-4.

36. Meni C, Bruneau J, Georgin-Lavialle S, Le Sache de Peufeilhoux L, Damaj G, Hadj-Rabia S, et al. Paediatric mastocytosis: a systematic review of 1747 cases. Br J Dermatol 2015;172:642-51. 